\title{
Sleep in older people
}

\author{
Michael Woodward \\ Aged and Residential Care Service, Heidelberg Repatriation Hospital, Melbourne, Australia
}

\section{Summary}

Insomnia and other sleep disturbances are common in older people, with up to $40 \%$ reporting some difficulty sleeping. Insomnia is a syndrome with multiple causes including medications, other illnesses and environmental factors. An accurate diagnosis is needed for effective management. Sleep disturbances are associated with functional and cognitive impairment and excess mortality. Management should initially be non-pharmacological including sleep hygiene education and behavioural therapy. Medications, including benzodiazepines (BZDs), are second-line with little evidence to support long-term usage. BZD usage in older people is associated with a range of disorders including falls, accidents and cognitive impairment. The management of insomnia in specific situations such as residential care, those with dementia and depressed older people can be challenging. Additional research is needed, particularly on the risks/benefit of long-term pharmacotherapy and to determine whether therapy reduces the consequences of sleep disturbances.

Key words: sleep, insomnia, morbidity, benzodiazepines, hypnotics.

\section{Introduction}

Sleep disturbances including insomnia are some of the most common complaints of older people and can significantly impact on quality of life. Despite this, they are rarely specifically asked about at encounters with health professionals. This may reflect either a trivialization of their significance or conflicting messages about optimum management. It is relatively easy to immediately prescribe a hypnosedative such as a benzodiazepine (BZD), yet the published literature is often critical of such an approach. Insomnia and sleep disturbances are not benign - they are associated with a range of morbidities, and even excess mortality, although this is difficult to separate from the effects of

Address for correspondence: Associate Professor Michael Woodward, Head of Aged and Residential Care Service, Heidelberg Repatriation Hospital, Austin Health, Waterdale Road, Heidelberg West, Victoria 3081, Australia. Email: michael.woodward@austin.org.au both the underlying causes and of hypnosedative therapy. Even less well known is whether the effective treatment of insomnia reduces these potential consequences. The management of sleep disturbances in older people can be particularly challenging in certain situations, including for those with dementia, depression and in residential care.

This is an evolving field, although there have been few recent major 'breakthroughs' in our understanding and management. Certainly, the better understanding of rapid eye movement sleep behaviour disorders and the newer hypnosedatives including melatonin-related therapies are advances, but we are a long way from eliminating sleep disturbances in older people.

This review is based on a search of recent published literature using the terms 'sleep', 'older', 'aged', 'insomnia', 'benzodiazepine' and 'hypnosedatives' along with key older research articles and reviews in the author's literature collection. The Australian National Presenting Service (NPS) has recently targeted insomnia and hypnosedative use in older people and provided a comprehensive literature search that was also used in this review.

\section{Sleep changes with ageing}

Sleep consists of two distinct states (Figure 1) rapid eye movement (REM) and non-REM (NREM). During the latter, neurological repair and restoration of physiological systems occur. NREM sleep can be divided into four further stages. Stage 1 is a transitional stage from awake to asleep, whereas stage 2 is the onset of sleep and constitutes the larger proportion of sleep time (around 50\%). During stage 2, the EEG shows rapid 'alpha' waves. People can be easily aroused from stage 1 and 2 sleep and some interpret these stages as not being truly asleep. Stages 3 and 4 sleep are the restorative deeper stages during which the EEG shows 'delta' waves. These two stages occur mainly during the first third of the night. 


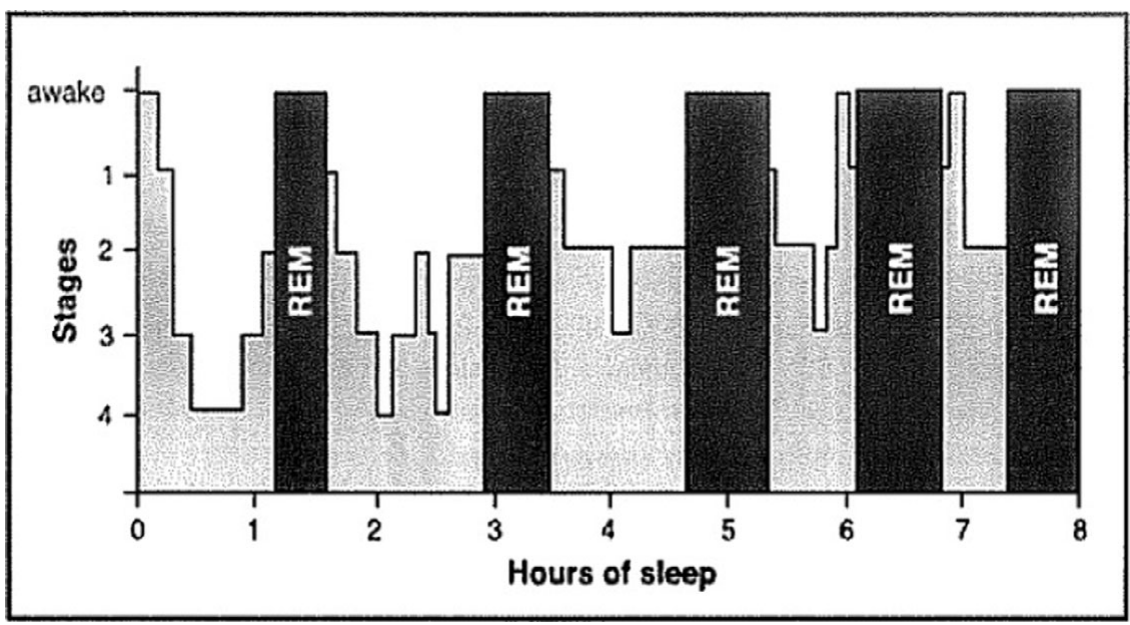

Figure 1. Sleep stages (adapted from Evaluation and Treatment of Insomnia by Anthony Kales and Joyce D. Kales (1984), p. 13, Fig. 1.4, by permission of Oxford University Press, Inc.)

Table 1. Sleep duration and architecture changes across the lifespan

\begin{tabular}{lcccr}
\hline \hline & $\begin{array}{c}\text { Sleep } \\
\text { duration } \\
(\text { hours })\end{array}$ & $\begin{array}{c}\text { Stage 1-2 } \\
(\%)\end{array}$ & $\begin{array}{c}\text { Stage 3-4 } \\
(\%)\end{array}$ & $\begin{array}{c}\text { REM } \\
(\%)\end{array}$ \\
\hline Infants & $13-16$ & $10-30$ & $30-40$ & $40-50$ \\
Children & $8-12$ & $40-60$ & $20-30$ & $20-30$ \\
Adults & $6-9$ & $45-60$ & $15-25$ & $15-25$ \\
Elderly & $5-8$ & $50-80$ & $5-15$ & $5-25$ \\
\hline \hline
\end{tabular}

REM sleep is associated with dreaming. Muscle and sympathetic tone drop but higher cortical brain function is active. Blood pressure, heart rate and respiratory rate vary throughout this stage. Alertness can be regained rapidly if awoken from this stage. REM sleep may be the stage where memories are consolidated. Deprivation of REM sleep results in a later rebound in REM sleep time, and long-term deprivation can have severe adverse health consequences, indicating the essential nature of this stage.

With increasing age, there is a change in sleep stages, with less REM and more stage 1 , but less stage 4, NREM sleep, as shown in Table 1 . This suggests impaired sleep maintenance and depth. Older people tend to have less total night-time sleep, but increased daytime napping. They often spend more time in bed at night, but less of this is spent asleep. ${ }^{1}$ This can be wrongly interpreted as difficulty sleeping.

\section{Insomnia in older people}

\section{Definition}

Insomnia, as clarified by the Diagnostic and Statistical Manual of Mental Disorders, 4th edition, Text Edition (DSM-IV TR), is a sleep disorder where the predominant complaint is difficulty initiating or maintaining sleep, or nonrestorative sleep, occurring at least 3 times a week for at least 1 month. This can be more formally defined as a delay of greater than 30 minutes in falling asleep and/or sleep efficacy (the percentage of time in bed and actually asleep) of less than $85 \%$. DSM-IV TR further states that the sleep disturbance, or associated daytime fatigue, must cause clinically significant distress or impairment in social, occupational or other important areas of functioning. Somewhat confusingly, DSM-IV TR states that insomnia cannot occur exclusively during the course of another sleep disorder (e.g. narcolepsy), or during a mental disorder (e.g. generalized anxiety), or be due to the direct psychological effects of a substance (e.g. drug abuse) or other medical condition. In essence, the DSM-IV TR criteria separate primary insomnia from what others call secondary insomnia.

Other ways of dividing this sleep disturbance labelled insomnia include 'acute' (less than 1 month duration) and chronic insomnia, transient (2-3 days)/short term (less than 3 weeks) and long-term, early/middle/late insomnia (difficulty falling asleep, maintaining sleep or waking too 
early) and mild/moderate/severe insomnia. Each has clinical usefulness. For the purpose of this review, insomnia will be that defined by DSMIV TR, except that in some situations it will not have persisted for a month (e.g. insomnia due to hospitalization/environmental changes).

\section{Prevalence}

Insomnia is a common condition. One-third of people have sleep disturbance fulfilling DSM-IV TR criteria for insomnia at some time, and $6 \%$ have such insomnia at any one time. Sleep dissatisfaction occurs in $8-18 \%$ of the population at any one time and daytime consequences of insomnia (fatigue, distress) are present in $9-15 \%$ of the population. Australian data show $32.6 \%$ of the population have symptoms of insomnia at any one time and $75 \%$ have had sleep difficulties over the previous year. ${ }^{2}$ Only $11 \%$ of people had sought help from a doctor specifically for insomnia - most had tried to self medicate (herbal or over-the-counter medicine) or had accepted prescription drugs from friends or family. Whilst these incidence and prevalence figures apply to the whole population, older people contribute significantly as sleep disorder symptoms are more common with increasing age.

A community study of 3000 people found $14 \%$ of those aged 18-34 years had insomnia compared with $25 \%$ of those aged $65-76$ years. ${ }^{3}$ A more recent German study found insomnia affected $4.1 \%$ of men and $3.1 \%$ of women aged $20-29$ years, but $12 \%$ of men and $35 \%$ of women over age 70 years. ${ }^{4}$ Dissatisfaction with sleep is also more common with older age, ${ }^{5}$ and complaints of sleep disturbance and transient $(<1$ month) insomnia affect $40 \%$ of the general population but over $50 \%$ of older people. ${ }^{6}$ Sleep disturbances are particularly of concern in residential care and hospital settings. ${ }^{7}$

An Australian community survey of 3300 people found older age is a risk factor for chronic daytime sleepiness. ${ }^{8}$ Daytime napping affects $25-46 \%$ of older people. ${ }^{9,10}$ Insomnia symptoms are more prevalent in older women than in older $\operatorname{men}^{9-11}$ but gender differences with daytime napping are not as well demonstrated. ${ }^{12}$

\section{Causes}

Old age itself is a risk factor for insomnia, for all sleep disturbances and for dissatisfaction with sleep, although few studies have included all co-morbidities to establish the independent contribution of old age. Similarly, it can be difficult to separate potential causes from consequences of sleep disturbances, with many appearing to be causative.

It is helpful to conceptualize sleep complaints as a multifactional geriatric syndrome, akin to other syndromes such as falls, incontinence and mobility disorders. Fragoso and Gill ${ }^{13}$ propose that sleep complaints and subsequent adverse outcomes can be caused by predisposing factors (normal ageing), precipitating factors (usual ageing) and perpetuating factors (which are usually psychosocial). Their model is shown in Figure 2.

Age-related changes in physiological functions cause the changes in the stages of sleep described above. These changes reflect changes in homeostatic mechanisms and circadian rhythms. Usual ageing is characterized by increased prevalence of a range of diseases, loss of function and also an increased prevalence of primary sleep disorders, and these can all precipitate sleep complaints and insomnia. Psychological factors that can precipitate sleep complaints include isolation, poor sleep hygiene, bereavement and the stresses of care-giving.

More often, the precipitating and predisposing factors are combined as 'causes' of insomnia and sleep complaints. An extensive, but by no means exhaustive, list of common causes and associations with sleep disturbance is shown in Table 2 . Some of these causes/associations warrant further discussion.

\section{Medications}

Medication use is greater in older than in younger people, with the mean number of different medications used by a communitydwelling older person being around $4 .{ }^{14}$ Some $44 \%$ of community-dwelling older Americans reported taking more than 5 medications in a week. ${ }^{15}$ On discharge from hospital, the mean number of medications taken by an older person rose from 6.8 in 1999 to 7.5 within 2 years. ${ }^{16}$ In residential care, the mean number of medications is around $6 .{ }^{17}$ Many medications can disturb sleep for instance, selective serotonin reuptake inhibitors (SSRIs) have been associated with reduced sleep efficiency and suppression of REM sleep. Even after excluding subjects with depression, SSRIs were associated with a greater chance of having 5 hours 

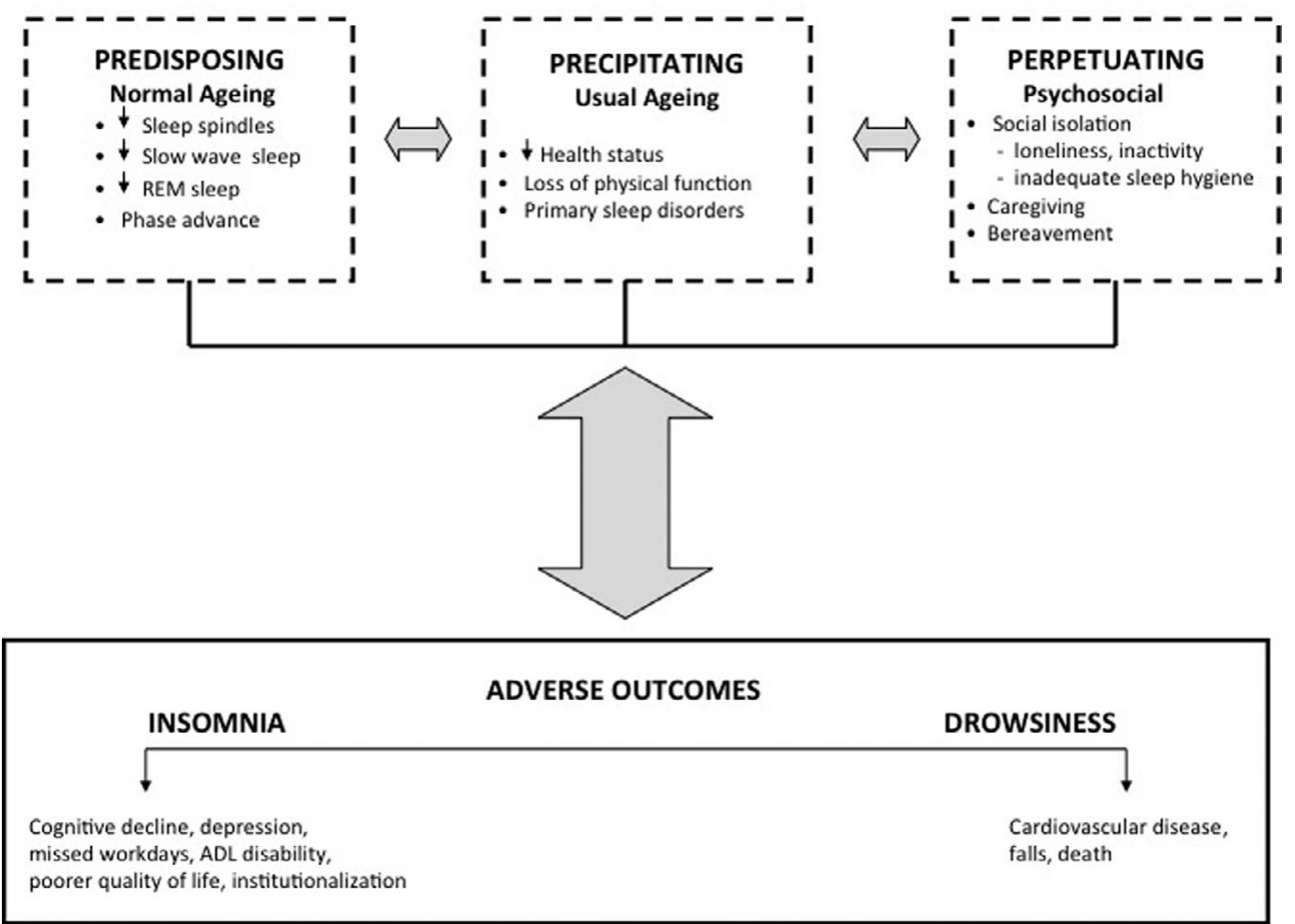

Figure 2. Mechanisms underlying sleep complaints and associated adverse outcomes ${ }^{13}$

or fewer sleep per night and sleep efficiency of less than $70 \% .{ }^{18}$ Medications that more frequently affect sleep, including causing insomnia, are those that act on the central nervous system, but other medications have been associated with insomnia. Adverse effects from medications (e.g. rash, urinary frequency, dyspepsia) are more common in older people and can also impact on sleep. Under-use of medications (e.g. to adequately treat pain, or to reduce nocturnal breathlessness from heart failure) can also impair sleep. Medications are also used extensively to improve sleep, as will be described below, and thus contribute both to polypharmacy in older age and the association between high medication use and sleep disturbance.

\section{Chronic medical conditions}

A range of medical conditions has been associated with impaired sleep, as outlined in Table 2. The list is not comprehensive - virtually any condition that causes discomfort by day can also affect sleep at night. Chronic physical conditions are very common in older people, with a recent USA National Sleep Foundation (NSF) poll showing $43 \%$ had $2-3$ chronic conditions, $24 \%$ had 4 or more and only $10 \%$ had none. ${ }^{10}$ Most of the more prevalent conditions can be directly linked to sleep problems. For instance cardiac failure is causally related to insomnia, Parkinson's disease is linked to REM behaviour disorder, and nocturia is reported by older people to be one of the symptoms most disruptive to sleep.

\section{Psychiatric and cognitive disorders}

Both cognitive impairment and dementia are associated with sleep disorders. In the NSF poll some $62 \%$ of the older respondents who felt they had memory problems also had insomnia. ${ }^{10}$ In a community-based study, self-reports of excessive daytime sleepiness were associated with cognitive impairment in several domains, including recall, orientation and attention. ${ }^{19}$ Dementia is associated with non-restorative sleep that has more stage 1 non-REM and less REM sleep along with 


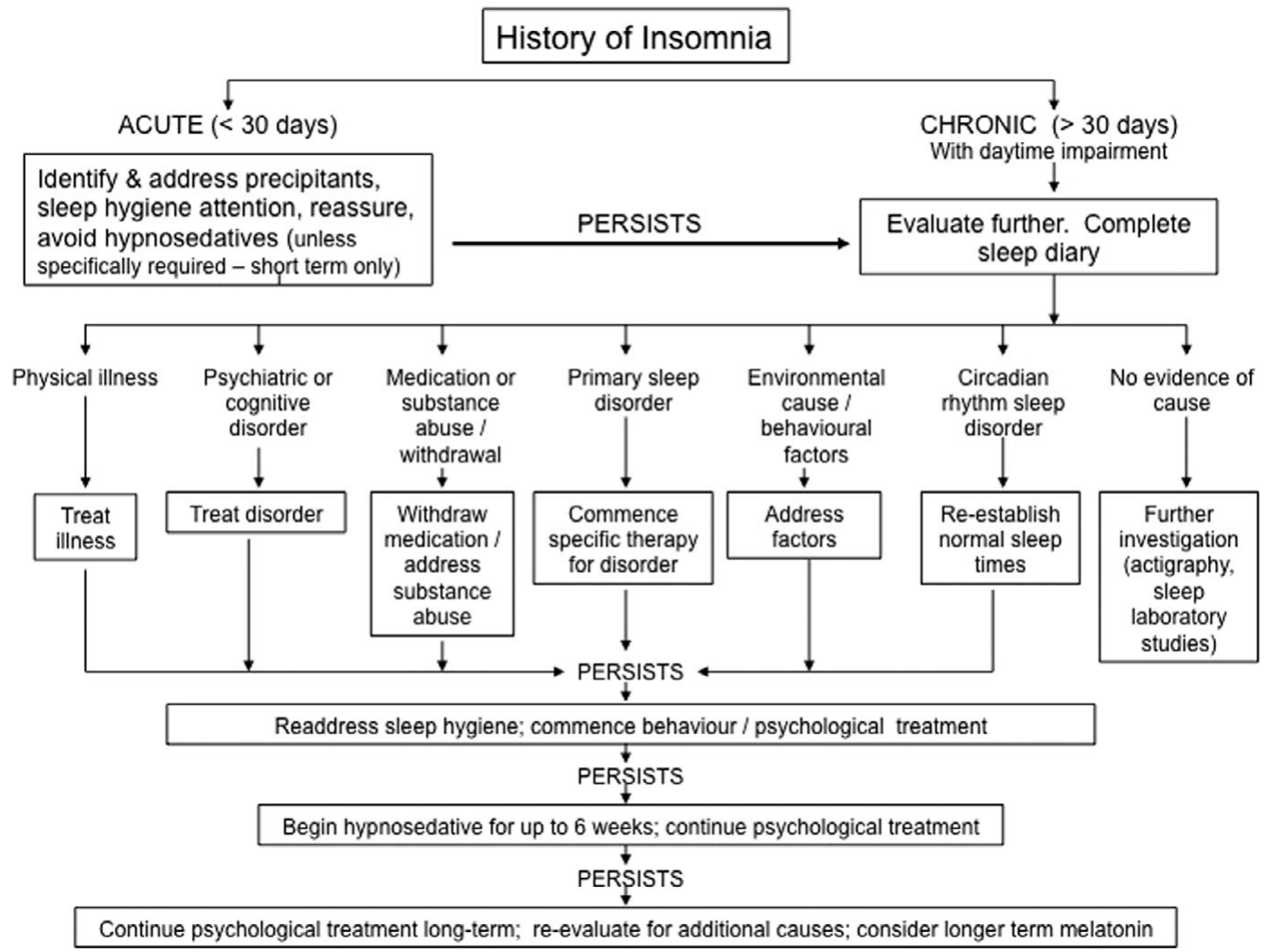

Figure 3. An approach to the evaluation and treatment of insomnia

more frequent nocturnal awakenings. ${ }^{20}$ Several conditions that can disrupt sleep are associated with dementia, including REM sleep behaviour disorder, psychosis and late afternoon agitation ('sundowning'). ${ }^{20}$

Depression is also strongly associated with sleep impairment. In the NSF poll, $70 \%$ of older people who self-reported depression had insomnia and $32 \%$ said they were drowsy by day. ${ }^{10}$ Numerous studies have shown an association between depression and insomnia, and it is likely that this link is causal. Resolution of depression, either spontaneously or by treatment, leads to improved sleeping, supporting the causal link.

Delirium is characterized by a disturbed sleep/wake cycle and poor night-time sleeping. Older people are more likely to develop a hypoactive form of delirium that can be difficult to distinguish from daytime sleepiness/drowsiness. They may also develop a mixed hypoactive/hyperactive delirium that can mimic a sleep disturbance. Delirium is very common in hospital settings, with up to $40 \%$ of older patients affected at some stage during their admission. ${ }^{21}$

Other more common psychiatric disorders that cause or are linked with sleep disorders are shown in Table 2, but this list is not comprehensive. For instance mania, paraphrenia and psychosis are all linked with impaired sleep.

\section{Consequences}

Insomnia and other sleep disturbances are far from benign. It can be difficult to distinguish between associations, causes and consequences of insomnia and the consequences of the treatments used for insomnia. Likely consequences of insomnia are shown in Table 3.

Some of these consequences have been subject to more rigorous evaluation. Poor reported sleep quality, prolonged sleep latency, daytime drowsiness, low sleep efficiency and sleepdisordered breathing have been associated with increased frailty, although causation has not been 
Table 2. Common causes and associations with sleep disturbance

\begin{tabular}{|c|c|}
\hline $\begin{array}{l}\text { Physical illness } \\
\text { - Arthritis } \\
\text { - Constipation } \\
\text { - Gastro-oesophageal reflux } \\
\text { - Nocturia, urinary retention } \\
\text { - Nocturnal angina } \\
\text { - Nocturnal breathlessness } \\
\text { - Other musculoskeletal pain }\end{array}$ & $\begin{array}{l}\text { - Other painful conditions } \\
\text { - Parkinson's disease } \\
\text { - Peptic ulceration } \\
\text { - Pruritus } \\
\text { - Stroke } \\
\text { - Thyroid disorders }\end{array}$ \\
\hline $\begin{array}{l}\text { Psychiatric and cognitive disorders } \\
\text { - Depression } \\
\text { - Delirium }\end{array}$ & $\begin{array}{l}\text { - Dementia, including dementia with Lewy bodies } \\
\text { - Anxiety disorders }\end{array}$ \\
\hline $\begin{array}{l}\text { Medications and other substances } \\
\text { - CNS stimulants: sympathomimetics, caffeine, } \\
\text { nicotine, antidepressants (e.g. selective serotonin } \\
\text { re-uptake inhibitors but not mirtazapine) } \\
\text { - Corticosteroids }\end{array}$ & $\begin{array}{l}\text { - Beta-blockers } \\
\text { - Alcohol (initially promotes sleep then rebound } \\
\text { insomnia } \\
\text { - Withdrawal from medications (e.g. BZDs) }\end{array}$ \\
\hline $\begin{array}{l}\text { Sleep disorders } \\
\text { - Sleep apnoea } \\
\text { - Restless legs syndrome }\end{array}$ & $\begin{array}{l}\text { - Periodic limb movements } \\
\text { - REM sleep disorders }\end{array}$ \\
\hline $\begin{array}{l}\text { Environmental factors } \\
\text { - Noise, light, ambient temperature - especially in } \\
\text { institutions }\end{array}$ & $\begin{array}{l}\text { - Bedding/bed } \\
\text { - Lack of exposure to sunlight }\end{array}$ \\
\hline $\begin{array}{l}\text { Behavioural factors } \\
\text { - Daytime napping } \\
\text { - Early retirement to bed } \\
\text { - Diet }\end{array}$ & $\begin{array}{l}\text { - Use of bed for other activities } \\
\text { - Lack of exercise }\end{array}$ \\
\hline $\begin{array}{l}\text { Circadian rhythm sleep disorders } \\
\text { - Advanced sleep phase } \\
\text { - Delayed sleep phase }\end{array}$ & - Time zone change syndrome \\
\hline
\end{tabular}

Table 3. Consequences of insomnia

\begin{tabular}{l}
\hline - Impaired function \\
- Frailty \\
- Poor self-rated health \\
- Cardiovascular disease \\
- Cognitive impairment \\
- Falls \\
- Depression \\
- Pain \\
- Mortality
\end{tabular}

fully established ${ }^{22,23}$ and insomnia itself was not independently associated with frailty. Daytime sleepiness has also been associated with functional impairment. ${ }^{24}$ In elderly nursing home residents, insomnia but not hypnotic use was found to be associated with a greater risk of falls, ${ }^{25}$ and an association between sleep problems and falls has also been found in community studies. ${ }^{26}$ Subjective sleep problems were found to predict cognitive decline over a period of 3 years in the Maastricht Ageing Study, ${ }^{27}$ and chronic insomnia, somewhat loosely defined, predicted incident cognitive decline over 3 years in a study of 6444 communitydwelling men and women from four sites in the US Established Populations for Epidemiological Studies of the Elderly Study. ${ }^{28}$

Perhaps the most concerning consequence of insomnia and sleep disturbance is mortality. Numerous community studies have shown increased mortality in those with daytime sleepiness, daytime napping and fatigue, ${ }^{29-32}$ but others have not found such an association. ${ }^{33,34}$ Interestingly, increased hours of evening sleep, rather than insomnia, have also been associated with increased mortality, ${ }^{31,35}$ suggesting that insomnia itself may not be causing increased mortality. Co-morbidity such as chronic physical illness and depression may be mediating the apparent association between 
sleep disturbances and increased mortality ${ }^{36}$ - this association needs further evaluation.

\section{Diagnosis}

The presence of insomnia should be established using recognized criteria such as DSM-IV TR. Other sleep disorders are diagnosed by their characteristic features and are described below. It is not enough to simply diagnose the presence of insomnia; a cause or contributing factors should also be sought (Figure 3).

There is a range of sleep assessment tools. A 2-week sleep diary designed by the American Academy of Sleep Medicine can be useful. ${ }^{37}$ The individual records use of stimulants such as coffee, taking medications, alcohol use and exercise. They record the time they go to bed and when they believe they fell asleep, and record whether they were asleep or awake throughout the 24-hour day. It is important to emphasize that they do not fill it in throughout the night. This diary, most importantly, can combat the mistaken perception that they are having very little sleep - for instance it may reveal that they are having 14 hours in bed overnight and whilst awake for 7 hours they are still having 7 hours sleep. It can also reveal excessive use of stimulants late in the day and insufficient exercise, amongst other useful information.

Other assessment approaches include a collaborative history from their bed partner or others who may be aware of them being awake or asleep overnight. Formal assessment tools include the 19-item self-rated Pittsburgh Sleep Quality Index (PSQI), the Insomnia Severity Index (ISI), the Sleep Problems Scale (SPS) and the Epworth Sleepiness Scale.

Tests that can be used in sleep disorder clinics and sleep laboratories include the multiple sleep latency tool (measuring speed to fall asleep), the maintenance of wakefulness test (the person is told to stay awake in a chair in a darkened room), polysomnography and actigraphy (the latter is especially useful in confirming the accuracy of a sleep diary).

A range of specialists may have interests and training in sleep disorders, including respiratory physicians, psychiatrists, geriatricians and neurologists - these are all a useful resource for more difficult cases. Sleep disorder clinics are found in larger cities and provide comprehensive assessment and management services.

\section{Other sleep disorders in older people}

Whilst insomnia is usually the focus of therapies for sleep disorders in older individuals, there are a range of other disorders that affect sleep and require both diagnostic and management skills.

\section{Restless legs syndrome and periodic limb movements in sleep}

These are the most common of the sleep-related movement disorders - approximately $10 \%$ of people over age 65 have restless legs syndrome, and this increases to $19 \%$ of those over the age of 80 years. This sleep disorder is characterized by an urge to move, particularly the legs, that worsens with inactivity and later in the day. About $80 \%$ of people with restless legs syndrome also have the other common sleep movement disorder, periodic limb movements in sleep, characterized by repetitive leg kicking (every 20-40 seconds) whilst asleep and often leading to awakenings. Restless legs syndrome may respond to dopaminergic therapy such as pramipexole, whilst the treatment of periodic limb movements in sleep usually requires specialist input.

\section{Sleep disordered breathing (including sleep apnoea)}

Sleep disordered breathing is common in older adults but frequently either not recognized or not diagnosed. Whilst prevalence studies based on sleep laboratory studies suggest a declining prevalence and severity with older age, communitybased studies show high morbidity attributable to sleep disordered breathing. Clinical manifestations in older people include cognitive impairment, loss of function, and increased risk of accidents such as falls and motor vehicle crashes. Cardiovascular consequences include stroke, ischaemic heart disease and hypertension. Diagnosis is based on symptoms, observations including of periods of apnoea overnight, loud snoring and daytime drowsiness. The definitive diagnostic test is a sleep study - an apnoea-hypopnoea index of 5 or greater diagnoses sleep disordered breathing but treatment may not be needed unless there are accompanying symptoms. For obstructive sleep apnoea, at least $70 \%$ of older people can tolerate the preferred treatment, continuous positive 
airways pressure (CPAP) overnight and it is worth persisting if initially CPAP is not tolerated. Central sleep apnoea may be secondary to insomnia, hypoxaemia, respiratory depressant medications and neurological disorders, and usually requires detailed input from sleep and other specialists.

\section{REM sleep behaviour disorder}

REM sleep behaviour disorder (RBD) is a sleep disorder in which patients appear to be enacting their dreams whilst in the REM stage of sleep. ${ }^{38}$ The behaviours can be quite violent, and are associated with violent dream content. Injury to self or bed partner can ensue. The disorder mainly affects older adults, with onset in the sixth and seventh decades, with a prevalence of around $0.5 \%$. The frequency is much higher, however, in certain neurodegenerative diseases such as dementia with Lewy bodies, Parkinson's disease and multi-system atrophy (Shy Drager syndrome). An idiopathic form can occur, but individuals with this may subsequently develop one of these neurodegenerative diseases. The underlying mechanism appears to be lack of normal REM muscle atonia and a lack of the normal suppression of locomotor generators during REM sleep. Alphasynuclein deposition in brainstem areas may be the main underlying pathology. It can occur when treatment with an antidepressant is commenced, or upon withdrawal of a hypnotic or of alcohol.

Whilst clonazepam is an effective therapy, a high risk of adverse effects in older people make it less useful in this age group. Slowrelease melatonin has demonstrated effectiveness in uncontrolled case studies, and there are also reports of responses to acetylcholinesterase inhibitors such as rivastigmine. Interventions to improve the safety of the sleep environment, and particularly to prevent injuries, are important.

\section{Management of insomnia}

\section{General advice}

After adequate assessment, initial management of insomnia should be treatment of identified causes. For example, excess caffeine should be reduced, late night meals avoided, pain treated and environmental noise reduced. These approaches should be combined with providing information
Table 4. Sleep bygiene

- Regular sleep hours

- Avoid excess time in bed

- Avoid daytime naps

- Use bed for sleep (and sexual activity) only

- Regular pre-retirement routine

- Schedule time to relax before bed

- Encourage physical activity by day

- Ensure sunlight exposure

- Make the bedroom quiet, comfortable, correct temperature, adequately dark and secure

- Minimize stimulants, especially after 5 pm

- Avoid large or late evening meal

about normal sleep patterns, and general sleep hygiene measures, as outlined in Table 4.

Usually these general, non-pharmacological approaches are sufficient, especially for acute insomnia. Before resorting to pharmacological approaches, other management options should be explored. These include cognitive behavioural therapy, and light therapy.

\section{Psychological treatment}

A range of psychological therapies has proved useful for the management of insomnia. There is a perception that older people respond less well to psychotherapy, but this is not supported by evidence. Useful approaches include:

- stimulus control: this associates the bedroom with sleep alone - prohibiting most other activities such as lying in bed watching TV.

- temporal control: this sets up a consistent time of waking and prohibits daytime napping.

- sleep restriction: time in bed is limited to short periods that are gradually increased.

- relaxation therapy: biofeedback and progressive muscle relaxation can be utilized. Listening to soothing music is also useful.

- paradoxical therapy: the fear of insomnia is reduced by encouraging the individual to remain awake for as long as possible.

- cognitive behavioural therapies (CBT): there is a wide range of CBT approaches that can be administered by trained health professionals who may not necessarily be psychologists.

Professionals who regularly manage individuals with insomnia and other sleep disorders are best 
suited to administer most of these approaches, but a family (general) physician trained in them can also utilize them with success. Even one or two 60-90 minute sessions can be efficacious.

The benefits of psychological approaches have been established in two meta-analyses, a systematic review and a review of 23 randomized controlled trials. Individual studies used a mixture of single behaviour therapy techniques and more formal CBT. ${ }^{39}$ Outcomes included improved sleep latency (by about $3 \mathrm{~min}$ ), reduced wake time after sleep onset (by about $22 \mathrm{~min}$ ), increased total sleep time (by $15 \mathrm{~min}$ ) and improved sleep quality. Effect sizes were generally around 0.6 , but ranged from 0.17 to 0.94 , with $0.2-0.3$ considered clinically meaningful.

In 2006 a task force commissioned by the American Academy of Sleep Medicine (AASM) published a revised report in order to update its practice parameters on psychological and behaviour therapies for insomnia. ${ }^{40}$ This systematic review was conducted on 37 studies comprising 2346 patients and provided findings consistent with the meta-analyses described above. The authors concluded that five treatments (stimulus control, relaxation, paradoxical therapy, sleep restriction and multimodal CBT) met criteria for empirically supported psychological therapies for insomnia. In addition, the changes in sleep parameters were well maintained at short (1-3 months), intermediate (6 months) and long term (>12 months) follow-ups, although there were few long-term studies, so the long-term data need to be interpreted with caution.

\section{Education}

Education programmes with literature and taperecorded instructions on progressive relaxation training have proved effective for up to 1 year. At that time, $90 \%$ of the individuals had been successfully trained, and $82 \%$ of them had experienced greater ease in falling asleep, staying asleep and reduced use of hypnosedatives. ${ }^{41}$ All non-pharmacological approaches should be accompanied by educational material.

\section{Light therapy}

Early studies suggested a benefit of bright light exposure, presumably via effects on the circadian rhythms. In a community study of older people with over 1 year of insomnia, daily exposure to bright light reduced the time awake at night by 1 hour and improved sleep efficiency from 78 to $90 \% .{ }^{42}$ Similar results have been demonstrated in a nursing home setting ${ }^{43}$ and in those with dementia. ${ }^{44}$ More recent studies show less convincing results. ${ }^{45}$ It may be that the timing of the light exposure and the intensity of the light moderate the effectiveness of this approach. Bright light (74,000 lux) has also been shown to improve performance in older people with sleep maintenance insomnia. ${ }^{46}$

\section{Other non-pharmacological approaches}

Low energy emission therapy utilizing an electrically conducing mouthpiece used for about 20 minutes in the late afternoon has been shown to increase sleep time, and acupuncture has also been utilized frequently for insomnia (both have been reviewed ${ }^{47}$ ). Daytime napping has been used successfully to increase the 24-hour sleeping time, ${ }^{48}$ and Tai Chi has been shown to improve selfrated sleep quality, reduce sleep onset latency (by $18 \mathrm{~min}$ ), and increase sleep duration (by $48 \mathrm{~min}$ ). ${ }^{49}$

\section{Non-pharmacological approaches in varied settings}

Most of the interventions described above were used in community settings. A sleep protocol for hospitalized elderly requesting a hypnotic has been shown to improve sleep quality as well as reduce use of hypnotics from 54 to $31 \%(P<$ 0.002)..$^{50}$ The regime included a back/shoulder rub, a warm non-stimulant bedtime drink, relaxation tapes and reduced environmental noise and light. In residential care (nursing homes) a multicomponent programme that included reduced time in bed, 30 minutes exposure to sunlight, increased physical activity, a structured bed-time routine and reduced night-time noise and light, resulted in improvements in night-time wakenings and daytime sleeping. ${ }^{51}$ In a separate study, however, a similar programme was not successful. ${ }^{52}$

\section{Utilizing non-pharmacological approaches}

Older people are usually open to a 'wait and see' approach to insomnia - this includes 
avoiding hypnosedatives and utilizing basic nonpharmacological approaches. Similarly, health professionals can be trained to avoid the 'prescription reflex' even though this may be different from current practice. One USA study of family physicians found $53 \%$ failed to ask about sleep, and $46 \%$ identified a prescription as best therapy. ${ }^{53}$ Non-pharmacological approaches should always be utilized, although the risks of not immediately reducing sleep deprivation (e.g. daytime drowsiness associated with some behavioural therapies) should be explained. In practice, both non-pharmacological and pharmacological approaches are often commenced together - indeed, there is some evidence that combined hypnotic and CBT is more effective than CBT alone acutely, but long-term outcome is optimized when the hypnotic is discontinued and CBT continued. ${ }^{54}$

\section{Pharmacological management}

Whilst there is justified concern about the overuse of BZDs and other modern hypnosedatives in older people, they represent a major advance over older agents and have a definite place in the management of insomnia and sleep disorders. The history of pharmacological management of sleep disorders shows how far we have come. Alcohol has been used for millennia, and still is, but the first drugs used specifically for hypnotic effects were the bromides in the 19th century. In 1903, barbiturates were first used, with a great deal of associated toxicity and morbidity. They were replaced by the much safer BZDs in the 1950s, with chlordiazepoxide (Librium) first used in 1959, then diazepam, from the same Roche Laboratory in 1963. The ' $Z$ ' drugs (e.g. zolpidem and zopiclone) were developed in the late 1980s. New hypnotics continue to be developed, with the melatonin receptor agonist ramelteon one of the most recent. The quest is for safer rather than necessarily more effective drugs, but this enthusiasm is sometimes overembraced by prescribers as a guarantee of safety. Correctly used, hypnotic agents are useful but there is still far too much, and inappropriate, use.

\section{Benzodiazepines (BZDs)}

Mechanism of action. These drugs act on the BZD receptor, which is adjacent to the $\gamma$-aminobutyric acid (GABA) receptor type $\mathrm{A}\left(\mathrm{GABA}_{\mathrm{A}}\right.$ receptor). GABA is the major inhibitory neurotransmitter in the human brain, exerting its action by binding at three different GABA receptors - A, B and C. BZD receptor binding changes the configuration of the GABA receptor to increase its affinity for GABA. The BZDs have six major therapeutic effects: anxiolytic, sedative/hypnotic, muscle relaxant, anticonvulsant, alcohol withdrawal treatment and amnesic effects. Specific drugs in this class are marketed for specific indications based on their differing pharmacokinetic profiles, but each drug may have therapeutic effects beyond its marketing approval.

Commonly used BZD hypnotics. The BZDs most commonly used for hypnotic effects are shown in Table 5. The most favourable pharmacokinetic profile in older people is exhibited by temazepam with metabolism by liver conjugation rather than CYP450 oxidation of the drug, a reasonably rapid onset of action and an acceptable elimination halflife. In many countries, including Australia, it is the most widely prescribed hypnotic BZD.

Prevalence of $B Z D$ prescribing. BZDs are the most prescribed psychotropic medication in a large number of countries - for instance, in Australia, anxiolytic, hypnotic and sedative BZD prescriptions make up $4-5 \%$ of the total prescriptions by general (family) practitioners. Long-term use increases markedly with older age. ${ }^{55}$ Some $15.7 \%$ of older Australians are chronic users of BZDs, and $19 \%$ of Australian adults have used a psychoactive drug in the previous 2 weeks. There is a high usage of BZDs in residential care facilities (around $28 \%$ ) and in hospitals $(36 \%$ in aged care wards in an Australian study).

Adverse effects of BZDs. Whilst BZDs are much safer than earlier hypnotics, they still have a wide range of adverse effects, as shown in Table 6. Particular concerns in older people include sedation, cognitive impairment, psychomotor impairment and discontinuation syndrome. The consequences of longer-term use in older people include falls, fractures, motor vehicle accidents and indeed increased mortality. ${ }^{56}$ The major drug interactions of concern are outlined in Table 7.

Effectiveness of BZDs for insomnia. The BZDs are effective for the short-term management of 
Table 5. Commonly used BZD hypnotics

\begin{tabular}{|c|c|c|c|c|}
\hline Name & $\begin{array}{l}\text { Approx. } \\
\text { equivalent } \\
\text { dose to } \\
\text { Diazepam } \\
5 \mathrm{mg}\end{array}$ & Length of action & Active metabolite & Elimination pathways \\
\hline Flunitrazepam & $1 \mathrm{mg}$ & $\begin{array}{l}\text { Very long (over } \\
100 \mathrm{~h} \text { ) }\end{array}$ & Yes (less active) & $\begin{array}{l}\text { Metabolism (mixed function } \\
\text { oxidase), renal excretion of } \\
\text { metabolites }\end{array}$ \\
\hline Flurazepam & $15 \mathrm{mg}$ & $\begin{array}{l}\text { Very long (over } \\
100 \mathrm{~h})\end{array}$ & Yes & $\begin{array}{l}\text { Metabolism, renal excretion } \\
\text { of metabolites }\end{array}$ \\
\hline Nitrazepam & $2.5 \mathrm{mg}$ & Long (over $20 \mathrm{~h}$ ) & Yes (very weak) & $\begin{array}{l}\text { Metabolism (nitroreduction, } \\
\text { acetylation), renal excretion } \\
\text { of metabolites }\end{array}$ \\
\hline Quazepam & $7.5 \mathrm{mg}$ & Long (over $20 \mathrm{~h}$ ) & Yes & Hydroxylation, conjugation \\
\hline Temazepam & $10 \mathrm{mg}$ & Short $(10-20 \mathrm{~h})$ & No & Conjugation \\
\hline Estazolam & $0.5 \mathrm{mg}$ & Short $(10-20 \mathrm{~h})$ & Yes (minimal contribution) & Hydroxylation (CYP3A4) \\
\hline Triazolam & $0.25 \mathrm{mg}$ & $\begin{array}{l}\text { Very short (less } \\
\text { than } 5 \mathrm{~h} \text { ) }\end{array}$ & No & Oxidation (CYP3A4) \\
\hline
\end{tabular}

Table 6. Adverse events associated with BZD use

\begin{tabular}{lll}
\hline \hline - Aggression & - Agitation & - Anorexia \\
- Ante-grade amnesia & - Auditory hallucinations & - Bitter or metallic taste \\
- Bizarre behaviour & - Constipation & - Delirium \\
- Depression & - Dry mouth & - Dysarthria \\
- Failure to ovulate & - Falls & - Flushing \\
- Gastro-intestinal complaints & - Genitourinary complaints & - Headache \\
- Hiccups & - Change in libido & - Increased appetite \\
- Increased salivation & - Joint pain & - Menstrual irregularities \\
- Muscle cramps & - Nausea & - Palpitations \\
- Panic & - Paranoid ideation & - Shortness of breath \\
- Swollen tongue & - Tachycardia & \\
- Vivid dreams & - Weight loss & \\
\hline \hline
\end{tabular}

insomnia. An analysis of 45 trials (2672 patients over 18 years of age) in which BZDs were used for a period ranging from 1 day to 6 weeks (mean 12 days), incorporated 15 trials including those aged 65 and over (4 exclusively in this age group). This analysis showed, compared with placebo, BZD use reduced sleep latency by 4.2 minutes and increased total sleep duration by 62 minutes. ${ }^{57}$ However, those on a BZD reported more daytime drowsiness, dizziness and cognitive decline.

There are no trials of BZDs, as hypnotics, beyond 12 weeks, so their long-term use for insomnia cannot be recommended. Practically, this means they should be used short term (up to 6 weeks) to improve sleeping patterns, then ceased. Combination with non-pharmacological therapies, which can be extended beyond 6 weeks upon cessation of the BZD, is recommended. ${ }^{54}$

\section{' $Z$ ' drugs}

Mechanism of action. These also interact with the $\mathrm{GABA}_{\mathrm{A}}-\mathrm{BZD}$ receptor complex to potentiate the inhibiting actions of GABA at the receptor. At least three types of BZD receptors have been described. The Z-drugs bind preferentially to the $\mathrm{BZD}_{1}$ receptor, in contrast to the BZDs, which non-selectively bind to, and activate, all BZD receptor subtypes. This selective binding of the $\mathrm{Z}$-drugs to the $\mathrm{BZD}_{1}$ receptor may explain their predominantly selective hypnotic properties and 
Table 7. Major drug interactions with hypnotic BZDs

\begin{tabular}{|c|c|c|c|}
\hline Precipitant drug & Object drug & Effect & Description \\
\hline Antacids & BZDs & Reduction & $\begin{array}{l}\text { Decreased absorption. } \\
\text { Staggered } \\
\text { administration is } \\
\text { recommended }\end{array}$ \\
\hline $\begin{array}{l}\text { Hepatic enzyme inhibitors (e.g. } \\
\text { ketoconazole, erythromycin, } \\
\text { clarithromycin, diltiazem, verapamil, } \\
\text { isoniazid, metroprolol, valproate) }\end{array}$ & $\begin{array}{l}\text { BZDs undergoing hepatic } \\
\text { oxidative metabolism - } \\
\text { e.g. triazolam, } \\
\text { nitrazepam }\end{array}$ & Increased & $\begin{array}{l}\text { Decreased elimination of } \\
\text { BZD. Dose reduction } \\
\text { often required }\end{array}$ \\
\hline Hepatic enzyme inducers & $\begin{array}{l}\text { BZDs undergoing hepatic } \\
\text { oxidative metabolism - } \\
\text { e.g. triazolam, } \\
\text { nitrazepam }\end{array}$ & Reduced & $\begin{array}{l}\text { Pharmacological effects } \\
\text { of some BZDs may be } \\
\text { decreased }\end{array}$ \\
\hline Grapefruit juice & Triazolam & Increased & $\begin{array}{l}\text { Increased } \\
\text { pharmacological effects } \\
\text { such as sedation and } \\
\text { psychomotor } \\
\text { impairment possible }\end{array}$ \\
\hline All BZDs & Levodopa & Reduced & $\begin{array}{l}\text { Possibly reduced efficacy } \\
\text { of levodopa in } \\
\text { Parkinson's disease }\end{array}$ \\
\hline
\end{tabular}

Table 8. Commonly used Z-drugs

\begin{tabular}{lllll}
\hline \hline Drug & Onset of action $(\mathrm{min})$ & Half-life $(\mathrm{h})$ & Elimination pathology & Active metabolite \\
\hline Zolpidem & 30 & 2.4 & CYP34A & No \\
Zopiclone & 30 & 5 & CYP34A and CYP2C8 & Yes (minor activity) \\
Eszopiclone & 30 & 9 & CYP3A4 and CYP2E1 & Yes \\
Zaleplon & 30 & 1 & Aldehyde oxidase and & No (based on animal \\
& & & CYP3A4 & studies) \\
\hline \hline
\end{tabular}

their minimal anxiolytic, muscle relaxant and antiepileptic properties.

Like the BZDs, the most important differences between the Z-drugs are their pharmacokinetics, particularly their duration of action, as outlined in Table 8.

\section{Adverse effects of Z-drugs}

Zolpidem has been associated with unusual reactions including bizarre behaviours such as sleepwalking, sleep eating and sleep driving, sometimes with fatal consequences. Other adverse effects include diarrhoea, dizziness, visual disturbances and changes in colour perception. The most common adverse effects reported with zopiclone use are a metallic taste and dry mouth.
Common drug interactions with the Z-drugs include increased central nervous system (CNS) depression with CNS depressants such as alcohol and opioids, increased plasma levels when administered with CYP34A inhibitors such as ketoconazole, erythromycin and ritonavir, and decreased plasma levels when given with hepatic enzyme inducers such as rifampicin, phenytoin and St John's Wort.

\section{Effectiveness of Z-drugs}

The short-term effectiveness (up to 6 weeks) of the Z-drugs was analysed in a meta-analysis that compared these drugs with a range of BZDs. ${ }^{58}$ The evaluations include 24 randomized 
controlled trials that compared either the $\mathrm{Z}$ drugs with several BZDs (17 trials) or any two of three Z-drugs (zopiclone, zolpidem, zaleplon (7 trials)). There were no significant variations in safety or efficacy between the Z-drugs and the BZDs. Minor differences were noted within the Z-drug class but the clinical significance was unknown.

In another meta-analysis confined to older people ( $>60$ years of age) with insomnia and otherwise free of psychiatric or psychological disorders, 24 randomized controlled short-term trials used either Z-drugs, several BZDs or an antihistamine (diphenhydramine) for at least 5 nights. ${ }^{59}$ The hypnotic group combined, compared with placebo, modestly improved sleep quality (effect size $0.14, P<0.05$ ), total sleep time (mean $25.2 \mathrm{~min}, P<0.001$ ), and the number of sleep awakenings decreased (by $0.63, P<0.001$ ). Adverse effects were, however, more common with hypnotic versus placebo - these included adverse cognitive effects, psychomotor effects and day-time fatigue. No differences were reported between the various drug groups; certainly the $Z$-drugs were at least as effective as the BZDs.

Longer-term effectiveness of the Z-drugs has been evaluated (unlike the BZDs). One study of 250 patients aged 59-95 years with chronic insomnia showed zaleplon used continuously for 1 year significantly improved sleep latency, number of awakenings and total sleep time $(P<0.001$ for each variable) for up to the full year. ${ }^{55}$ Sleep latency improved from a baseline mean of $79.6 \pm 47.0$ $\min$ to $44.4 \pm 33.6 \mathrm{~min}$ at 1 year, and total sleep time improved from $300.2 \pm 67.8$ to $356.7 \pm 71.0$ min. It was, however, an open-label single-blind extension study.

In another randomized, double-blind placebocontrolled trial to determine the long-term effectiveness of eszopiclone, nearly 800 patients aged 21-69 years with primary insomnia were treated nightly for 6 months. ${ }^{60}$ Eszopiclone produced significant improvements in sleep latency, number of awakenings and total sleep time compared with placebo $(P=0.003)$ and these improvements were sustained over the 6-month period. The most common adverse events were unpleasant taste and headaches. To date, eszopiclone is the only hypnotic approved by the USA FDA for use longer than 35 days. It is to be noted, however, that this trial did not include people over 70 years of age.

\section{Efficacy of BZD and Z-drugs compared with behavioural therapies}

A number of clinical trials have assessed the efficacy of the BZD and Z-drugs combined with, or compared with, behavioural therapy in the treatment of insomnia. These generally show shortterm benefits of the hypnotic but longer term benefits only from behavioural therapy. A metaanalysis comparing pharmacological and nonpharmacological treatments included 21 studies (7 only had pharmacological treatment, 13 only behavioural and one compared both) and showed comparable short-term effectiveness (2-4 weeks) for both psychological/behavioural treatments and pharmacotherapy in patients (of all ages) with primary insomnia. ${ }^{61}$ The 2009 study by Morin et al., ${ }^{54}$ referred to above, examined long-term intermittent zolpidem therapy (6 months) in conjunction with CBT in 160 patients with persistent insomnia. There were added benefits of the combined therapies compared with either alone in the acute phase, but longterm outcome was optimized when medication was discontinued, rather than continued, during long-term maintenance CBT. This is an extremely important finding as it demonstrates not only the benefits of long-term behavioural therapy but also the importance of NOT continuing hypnotic therapy long term.

\section{Melatonin and related therapies}

Melatonin may be useful in those who have insomnia related to circadian rhythm disturbances, especially where they have difficulty falling asleep. Initial short studies (up to 7 weeks) with standard melatonin failed to show benefits, but more recent studies with a controlled (slow) release formulation have demonstrated effectiveness. In a large, randomized double-blind, placebocontrolled study (354 individuals), which included patients aged 55-80 years, 3 weeks treatment with controlled release melatonin was associated with significant improvements in sleep scales, daytime alertness, quality of life and sleep latency (13 $\mathrm{min}$, compared with 25 with placebo). ${ }^{62}$ Other studies have shown similar benefits, ${ }^{63}$ with newer research suggesting that benefits persist beyond 3 weeks.

The melatonin receptor agonist ramelteon has also been shown to be effective in older people. A trial in 829 individuals over 65 showed an 
improvement in sleep latency with up to 5 weeks of therapy (17 versus $37 \mathrm{~min}$ at 5 weeks). ${ }^{64}$ This drug has now been approved in several countries.

Attractions of melatonin-based therapies include safety and the low risk of dependency/abuse, although long-term data are still lacking. Melatonin can potentially cause coronary vasoconstriction, but this has not been found in the trials. The study of ramelteon showed a slightly higher rate of dysgeusia (altered taste) and dizziness in the ramelteon-treated group compared with the placebo-treated group.

\section{Valerian}

This herb has long been regarded as a safe, effective sleep-promoting agent. A systematic review, however, produced inconsistent results ${ }^{65}$ and a recent small study showed no benefit. ${ }^{66}$ Another recent trial showed benefits on sleep latency if used with hops, but not if used alone. ${ }^{67}$ Daytime sleepiness from valerian has been reported, and there have been rare cases of hepatotoxicity.

\section{Other drugs}

Antidepressants may be beneficial when depression or anxiety is associated with insomnia, but their side-effect profile in older people makes them inappropriate as first-line therapy for insomnia not associated with these disorders. There are no studies of antipsychotic agents, including the newer 'atypical' agents, for insomnia and again the risk of adverse effects precludes their use for insomnia alone. Sedating antihistamines have been shown to have some beneficial effects on insomnia but they also can reduce sleep quality, increase daytime drowsiness and rapidly induce tolerance. Their side-effects profile also makes them inappropriate as treatment of insomnia in older individuals.

\section{Recommended use of pharmacological management of insomnia}

Pharmacological therapy should only be utilized when non-pharmacological approaches have failed after an appropriate period (3-6 weeks ideally). In some settings, however, where adequate sleep is needed immediately (e.g. in rehabilitation units), it may be appropriate to initiate pharmacotherapy after a shorter period. Non-pharmacological approaches should be continued along with pharmacotherapy. As there is little evidence to support long-term use of hypnotic agents, and as all are associated with adverse effects, therapy should not be continued beyond 6 weeks - a possible exception is slow release melatonin, which is relatively safe and has been shown to be effective for up to 13 weeks. Cessation of the hypnotic after 6 weeks may enhance the longer-term benefits of ongoing behavioural therapy.

Preferred BZD receptor acting agents in older people are temazepam (initially $5-10 \mathrm{mg}$ ), zolpidem $(5-10 \mathrm{mg}$ ) and zopiclone $(3.75-7.5 \mathrm{mg}$ ). Slow-release melatonin is an alternative choice.

Recently the American Academy of Sleep medicine produced a recommended hierarchy of pharmacological approaches to the management of chronic insomnia in adults. ${ }^{68}$ They recommended only short-term use of a hypnotic and supplementing this with behavioural and cognitive therapies when possible. When pharmacological therapy is utilized, the choice of a specific pharmacological agent should be directed by factors including patient preferences, the symptom pattern, past treatment responses, co-morbid conditions and adverse effects of the agent. They recommended one of temazepam, zolpidem, zaleplon, eszopiclone or ramelteon as the first choice and trialling another drug from this group of five if the first choice fails. They somewhat surprisingly then recommend a sedating antidepressant, but couch this by saying this is especially when there is co-morbid depression/anxiety. Most specialists in the treatment of older adults would be far more cautious in the use of these agents if there were no depression or anxiety. The guidelines also state that, if there is epilepsy or psychosis, sedating agents used for these conditions may also assist sleep but they should not be utilized in the absence of the primary indication. They state that antihistamines, analgesics and herbal or nutritional substances (including valerian and immediaterelease melatonin) are not recommended for chronic insomnia, nor are all other agents (e.g. barbiturates and chloral hydrate). They recommend an initial 2-4 week trial, and utilization of the lowest effective dose. The guidelines were produced before controlled-release melatonin had been sufficiently evaluated. 


\section{Deprescribing bypnotic agents}

BZD and Z-drug overuse and abuse are major concerns. Long-term use of these medications is associated with tolerance and dependence. Risk factors for these include psychiatric co-morbidity, older age, an avoidance style of coping, lower education and longer-term use. Tolerance to the hypnotic effects of these agents can develop within days to a few weeks, and is to be distinguished from the much longer time to develop tolerance to anxiolytic effects (4-6 months). This tolerance may lead to dose escalations and a higher risk of adverse effects. Dependence may be physiological, leading to withdrawal symptoms when ceased, and psychological - including fear/anxiety (especially at the thought of discontinuation), loss of confidence and drug-seeking behaviour.

It is thus essential to avoid unnecessary longer term use of these agents, and to cease/reduce ('deprescribe') them whenever possible. Discontinuation syndromes include confusion, anxiety, temporarily increased insomnia and autonomic features. These can be overcome by patient education, treatment of withdrawal symptoms and ongoing support. There is a lack of clear guidelines but several articles have specifically addressed deprescribing hypnotics in older individuals. ${ }^{69-71}$ There is support for substituting an equivalent dose of a longer-acting drug such as diazepam, then slowly tapering (e.g. from $15 \mathrm{mg}$ diazepam to cessation over 26 weeks). Other approaches, including non-substitution with sudden cessation or cessation through utilization of alternative, then every third and so on, night use of the initial shorter-acting agent, also have support.

The recreational use of agents such as BZDs is beyond the scope of this review but is not confined to younger people. Easy availability of large quantities of these agents may promote this, and monitoring use as well as ongoing attempts to deprescribe are essential.

Treatment of sleep disorders in common geriatric syndromes and situations

\section{Dementia}

All forms of cognitive impairment, including mild cognitive impairment, are associated with an increased risk of sleep disorders including insomnia, which affects up to $70 \%$ of people with cognitive impairment. Dementia with Lewy bodies seems to carry the highest risk of sleep disturbance. Pharmacological treatment of insomnia can lead to cognitive decline. The long-acting BZDs are most commonly associated with cognitive impairment in this population, and longer terms of use of these agents pose a greater risk than short-term use. The cognitive impairment is manifested by anterograde amnesia, reduced short-term recall and increased forgetfulness. BZD use and withdrawal is a risk factor for delirium, commonly in the in-patient setting.

It is thus important to give preference to non-pharmacological over pharmacological management of sleep disorders in those with cognitive impairment, and to deprescribe hypnotic agents in these individuals wherever possible. If a hypnotic must be used, short courses of shorter acting BZD receptor agents such as temazepam or possibly the use of slow-release melatonin, are preferable. The aim should always be to cease pharmacological management as soon as possible.

Caregivers can also suffer insomnia, especially if depressed, and this also needs to be recognized and managed. Indeed, caregiving is associated with poorer health, poorer quality of life and even increased mortality, and this may be partly mediated by sleep disturbances in the caregivers.

\section{Depression}

Depression is a very common disorder in older age but is often mis-diagnosed and incorrectly treated. If insomnia or anxiety are presenting features, a BZD may be inappropriately used as first-line therapy. Many studies have found a strong association between BZD use and depression, suggesting that BZD use may actually lead to or prolong depression. In a study of 599 subjects aged 85 years at baseline and followed for 5 years, BZD users were 1.6 times more likely $(95 \% \mathrm{CI}=$ $1.05-2.55, P=0.028)$ to develop new depressive symptoms. ${ }^{72}$ Thus it is important to diagnose depression in those with sleep disorders such as insomnia, and to treat this with an appropriate antidepressant rather than a hypnotic agent. More sedating antidepressants may be preferable when insomnia is a prominent feature, but need to be used with caution in those prone to falls and confusion. Again, if a hypnotic is needed, a shortacting agent is preferable. Newer antidepressants 
acting on the melatonin pathway may also be agents of choice in this situation but more evidence is needed to support this.

\section{Hip fractures and falls}

A range of sedatives have been associated with a greater risk of hip fractures and falls in older adults, especially the longer acting BZDs. Thus where an individual prone to falls is suffering from insomnia, non-pharmacological approaches are vital, and hypnotics such as a BZD should not be initiated, especially in the in-patient setting, where falls risk is often even higher. Deprescribing these agents is vital. It is encouraging that there is evidence that clinicians are less likely to prescribe a BZD for people with established risk factors for falls, but overuse of these agents in this high-risk group is still a major concern.

\section{Motor vehicle accidents}

BZDs, presumably by their effects on psychomotor and cognitive functions, have been associated with increased risk of motor vehicle accidents in older individuals. Thus use of these agents in older drivers with insomnia should be avoided wherever possible. The risk of crashes is greater in the first week of usage, so avoiding initiation is probably more important than deprescribing these agents. Deprescribing, however, remains a high priority if these agents are being used in those who are driving. Parasomnias such as sleepdriving, associated with zolpidem and possibly other hypnotics, also contribute to the link between crashes and hypnotic use.

\section{In-patient settings}

There is a high prevalence of BZD prescribing to elderly in-patients, predominantly to promote sleep. It is ideal to keep such medications use to a minimum and discontinuation of these drugs is often appropriate. An algorithm has been developed to assess the appropriateness of BZD prescribing amongst in-patients (Figure 4) and this can be used both to guide deprescribing and to audit appropriateness of BZD use in this setting. ${ }^{73}$ Audit results fed-back to the prescribing team, along with educational material about the dangers of BZD use in the older in-patient, has been shown to both reduce overall BZD prescribing and also to increase the appropriateness of remaining prescribing. A sleep protocol for in-patients, described above, provides an alternative to the use of BZDs and other hypnotics in this setting.

\section{Residential care}

As in hospitals, there is often excessive use of hypnotics in residential care facilities, especially when the frailty, prevalence of co-morbidity and extreme age of many of the residents is considered. Deprescribing, and limiting new prescribing, should be the aim. Non-pharmacological approaches, described above, should be utilized well before medications are considered. It is vital, however, to try to improve sleep - poor sleep in residential care has been associated with declining function, declining quality of life and greater risk of depression. ${ }^{74}$

\section{Palliativelend of life care}

Hypnotic and sedative therapy is often appropriate in the palliative care setting. Agitation and insomnia are common as people approach the end of life and even deep sedation (palliative or terminal sedation) may be clinically and ethically appropriate. This deep sedation is administered to up to $50 \%$ of terminally ill patients with refractory symptoms. The agents used differ from those used primarily as hypnotics, but they do have sleeppromoting activity. Commonly used agents include midazolam, clonazepam and diazepam.

\section{Conclusions}

Sleep disorders are a major clinical issue for older adults, and whilst advances have been made in diagnosis and management, there is still a major need for effective approaches to safely treat the spectrum of sleep problems. The dangers of undertreated sleep disturbance may outweigh the risk of adverse effects of the hypnotic agent, but treatment without medication should almost always be the first approach. If a hypnotic agent is required, the preferred agents are short-acting BZDs and Zdrugs such as temazepam, zopiclone and zolpidem. Longer-term use has very little supportive evidence 


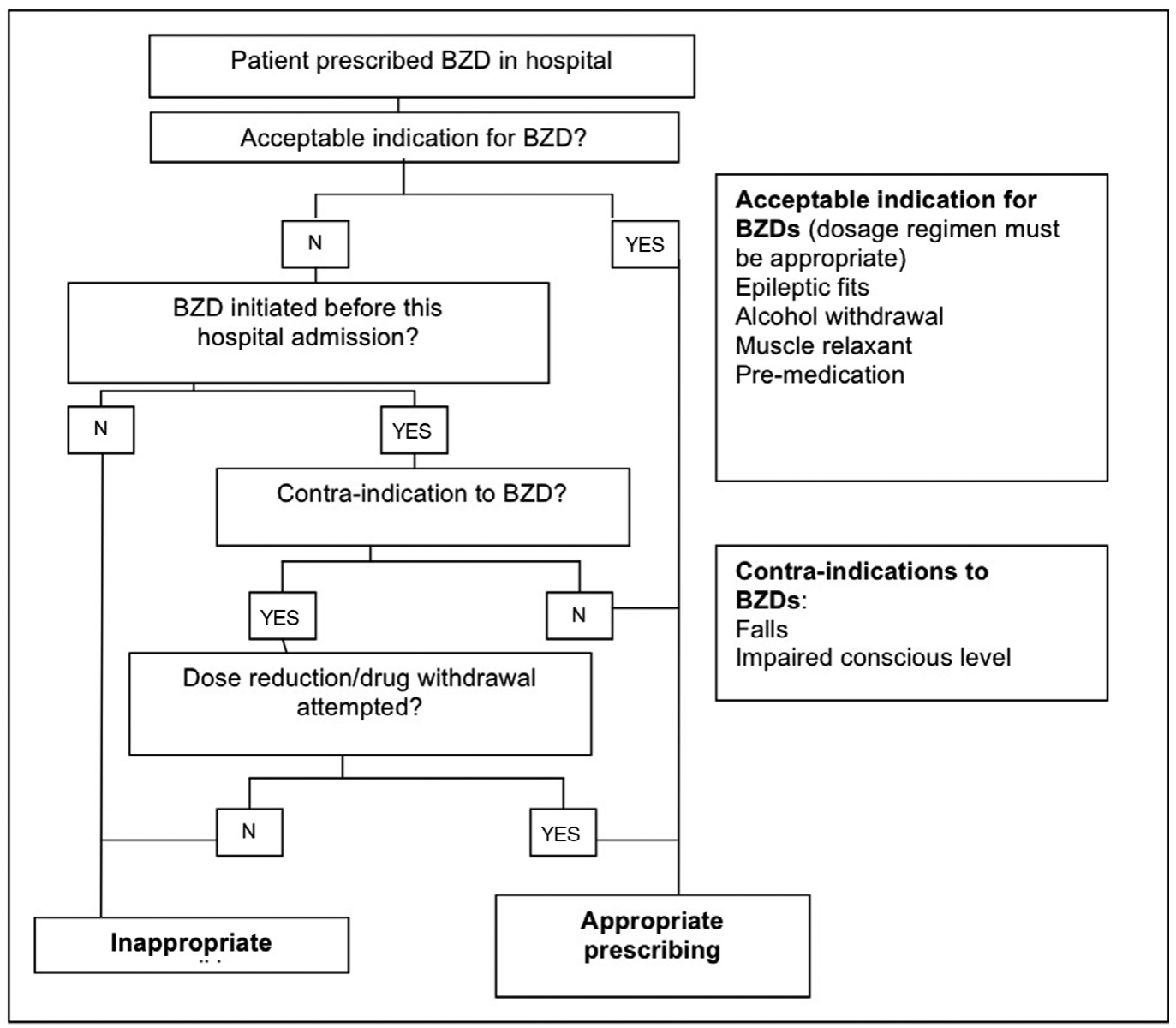

Figure 4. Algorithm to assess appropriateness of prescribing BZDs in hospital in-patients over age 64 years ${ }^{73}$

from controlled trials and should be avoided. Deprescribing hypnotics is as important as limiting their initiation.

There is a clear need for additional research across a range of issues:

- risks/benefits of longer term hypnotic use.

- translational research - more effectively bringing non-pharmacological approaches into common clinical settings.

- prevention of sleep disorders. For instance, can better detection and management of prodromal dementia with Lewy bodies or prodromal Alzheimer's disease reduce the risk of sleep disorders developing?

- the benefits of treating sleep disorders on the subsequent development of co-morbidity and even mortality.
- the development of more effective and/or safer hypnotic agents. Melatonin-targeted therapies may provide this but more data are needed on longer-term safety and efficacy.

\section{Conflicts of interest}

The author has no conflicts of interest relevant to any of the management approaches or clinical issues discussed in this article.

\section{References}

1 Unruh ML, Redline S, An MW, Buysse DJ, Nieto FJ, Yeh JL, Newman AB. Subjective and objective sleep quality and ageing in the sleep heart health study. J Am Geriatr Soc 2008; 56: 1218-27. 
2 Bartlett DJ, Marshall NS, Williams A, Grunstein RR. Predictors of primary medical care consultations for sleep disorders. Sleep Med 2008; 9: 857-64.

3 Mellinger GD, Bolten MB, Uhlentruth EH. Insomnia and its treatment. Arch Gen Psychiatry 1985; 42: 225-32.

4 Weyerer A, Dilling M. Prevalence and treatment of insomnia in the community: results from the Upper Bavarian Field Study. Sleep 1991; 14: 392-98.

5 Jacobs JM, Cohen A, Hammerman-Rozenberg R, Stessman J. Global sleep satisfaction of older people: the Jerusalem cohort study. J Am Geriatr Soc 2006; 54: 325-29.

6 Ancoli-Israel S. Epidemiology of sleep disorders. Clin Geriatr Med 1989; 5: 347-62.

7 Fetveit A, Bjorvatn B. Sleep disturbances among nursing home residents. Int J Geriatr Psychiatry 2002; 17: 604-9.

8 Bartlett DJ, Marshall NS, Williams A, Grunstein RR. Sleep health in New South Wales: chronic sleep restrictions and daytime sleepiness. Intern Med J 2008; 38: 24-31.

9 Foley DJ, Monjan AA, Brown SL, Simonsick EM, Wallace RB, Blazer DG. Sleep complaints among elderly persons: an epidemiologic study of three communities. Sleep 1995; 18: 425-32.

10 National Sleep Foundation 2003. Sleep in America Poll 2003. Sleep and Ageing (online). Available at: www.sleepfoundation.org (accessed 1 June 2011).

11 Ohayon MM, Zulley J, Guilleminault C, Smirne S, Priest RG. How age and daytime activities are related to insomnia in the general population: consequences for older people. J Am Geriatr Soc 2001; 49: 360-66.

12 Ancoli-Israel S, Martin JL. Insomnia and daytime napping in older adults. J Clin Sleep Med 2006; 2: 333-42.

13 Fragoso CAV, Gill TM. Sleep complaints in community-living older persons: a multifactorial geriatric syndrome. J Am Geriatr Soc 2007; 55: 1853-66.

14 Cohen I, Rogers P, Burke V, Beilin LJ. Predictors of medication use, compliance and symptoms of hypotension in a community-based sample of elderly men and women. J Clin Pharm Ther 1998; 23: 423-32.

15 Kaufman DW, Kelly JP, Rosenberg L, Anderson TE, Mitchell AA. Recent patterns of medications use in the ambulatory adult populations of the United States. JAMA 2002; 287: 337-44.

16 Scott I, Jayathissa S. Quality of drug prescribing in older patients: is there a problem and can we improve it? Intern Med J 2010; 40: 7-18.
17 Tjia J, Rothman MR, Kiely DK, Shaffer ML, Holmes HM, Sachs GA, Mitchell SL. Daily medications use in nursing hoime residents with advanced dementia. J Am Geriatr Soc 2010; 58: 880-88.

18 Ensrud KE, Blackwell TL, Ancoli-Israel S, Redline S, Yaffe K, Diem S, Claman D, Stone KL; for the Study of Osteoporotic Fractures Research Group. Use of selective serotonin reuptake inhibitors and sleep disturbance in community-dwelling older women. J Am Geriatr Soc 2006; 54:1508-15.

19 Obayon MM, Vecchierinni M-F. 2002. Daytime sleepiness and cognitive impairment in the elderly populations. Arch Intern Med 2002; 162: 201-8.

20 Moran M, Lynch CA, Walsh C, Coen R, Coakley $\mathrm{D}$, Lawlor BA. Sleep disturbance in mild to moderate Alzheimer's disease. Sleep Med 2005; 6: 347-52.

21 Levkoff SE, Evans DA, Liptzin B, Cleary PD, Lipsitz LA, Wetle TT, Reilly CH, Pilgrim DM, Schor J, Rowe J. Delirium. The occurrence and persistence of symptoms among elderly hospitalised patients. Arch Intern Med 1992; 152: 334-40.

22 Ensrud KE, Blackwell TL, Redline S, Ancoli-Israel S, Paudel ML, Cawthon PM, Dam TT, Barrett-Connor E, Leung PC, Stone KL; Osteoporotic Fractures in Men Study Group. Sleep disturbances and frailty status in older community-dwelling men. J Am Geriatr Soc 2009; 57: 2085-93.

23 Fragoso CAV, Gahbauer EA, Van Ness PH, Gill T. Sleep-wake disturbances and frailty in community-living older persons. J Am Geriatr Soc 2009; 57: 2094-100.

24 Gooneratne NS, Weaver TE, Cater JR, Pack FM, Arner HM, Greenberg AS, Pack AI. Functional outcomes of excessive daytime sleepiness in older adults. J Am Geriatr Soc 2003; 51: 64249.

25 Avidan AY, Fries BE, James ML, Szafara KL, Wright GT, Chervin RD. Insomnia and hypnotic use, recorded in the minimum date set, as predictors of falls and hip fractures in Michigan nursing homes. J Am Geriatr Soc 2005; 53: 955-62.

26 Brassington GS, King AC, Bliwise DL. Sleep problems as a risk factor for falls in a sample of community-dwelling adults aged 64-99 years. J Am Geriatr Soc 2000; 48: 1234-40.

27 Jelicic M, Bosma H, Ponds RW, Van Boxtel MP, Houx PJ, Jolles J. Subjective sleep problems in later life as predictors of cognitive decline. Report from the Maastricht Ageing Study (MADS). Int J Geriatr Psychiatry 2002; 17: 73-77. 
28 Cricco M, Simonsick EM, Foley DJ. The impact of insomnia on cognitive functioning in older adults. J Am Geriatr Soc 2001; 49: 1185-89.

29 Newman AB, Spiekerman CF, Enright P, Lefkowitz D, Manolio T, Reynolds CF, Robbins J. Daytime sleepiness predicts mortality and cardiovascular disease in older adults. $\mathrm{J} \mathrm{Am}$ Geriatr Soc 2000; 48: 115-23.

30 Bursztyn M, Ginsberg G, Hammerman-Rozenberg $\mathrm{R}$, Stressman J. The siesta in the elderly. Risk factor for mortality? Arch Intern Med 1999; 159 : 1582-86.

31 Stone KL, Ewing SK, Ancoli-Israel S, Ensrud KE, Redline S, Bauer DC, Cauley JA, Hillier TA, Cummings SR. Self-reported sleep and nap habits and risk of mortality in a large cohort of older women. J Am Geriatr Soc 2009; 57: 604-11.

32 Hardy SE, Studenski SA. Fatigue predicts mortality in older adults. J Am Geriatr Soc 2008; 56: 1910-14.

33 Althuis MD, Fredman L, Langenberg PW, Magaziner J. The relationship between insomnia and mortality among community-dwelling older women. J Am Geriatr Soc 1998; 46: 1270-73.

34 Rockwood K, Davis HS, Merry HR, MacKnight $\mathrm{C}, \mathrm{McD}$ owell I. Sleep disturbances and mortality: results from the Canadian Study of Health and Ageing. I Am Geriatr Soc 2001; 49: 639-41.

35 Mesas AE, Lopez-Garcia E, Leon-Munoz LM, Guallar-Castillon P, Rodriguez-Artalejo F. Sleep duration and mortality according to health status in older adults. J Am Geriatr Soc 2010; 58: 1870-77.

36 Gureje O, Kola L, Ademola A, Olley BO. Profile, comorbidity and impact of insomnia in the Ibadan Study of Ageing. Int J Geriatr Psychiatry 2009; 24: 686-93.

37 Sleep diary at: www.sleepeducation.com/pdf/ sleepdiary.pdf (accessed 1 June 2011).

38 Trotti LM. REM sleep behaviour disorder in older individuals. Epidemiology, pathophysiology and management. Drugs Aging 2010; 27: 457-70.

39 Riemann D, Perlis ML. The treatment of chronic insomnia: a review of benzodiazepine receptor agonists and psychological and behavioural therapies. Sleep Med Rev 2009; 13: 205-14.

40 Morin CM, Bootzin RR, Buysse DJ, Edinger JD, Espie CA, Lichstein KL. Psychological and behavioural treatment of insomnia: update of the recent evidence (1998-2004). Sleep 2006; 29 : $1398-414$

41 Gustafson R. Treating insomnia with a self-administered muscle relaxation training program: a follow-up. Psychol Rep 1994; 70: 124-26.
42 Campbell SS. Alleviation of sleep maintenance insomnia with timed exposure to bright light. J Am Geriatr Soc 1993; 41: 829-36.

43 Ancoli-Israel S, Martin JL, Kripke DF, Marler M, Klauber MR. Effect of light treatment in sleep and circadian rhythms in demented nursing home patients. J Am Geriatr Soc 2002; 50: 282-89.

44 Sloane PD, Williams CS, Mitchell CM, Preisser JS, Wood W, Barrick AL, Hickman SE, Gill KS, Connell BR, Edinger J, Zimmerman S. High-intensity environmental light in dementia: effect on sleep activity. J Am Geriatr Soc 2007; 53: 1524-33.

45 Friedman L, Zeitzer JM, Kushida C, Zhdanova I, Noda A, Lee T, Schneider B, Guilleminault C, Sheikh J, Yesavage JA. Scheduled bright light for treatment of insomnia in older adults. $J \mathrm{Am}$ Geriatr Soc 2009; 57: 441-52.

46 Murphy PJ, Campbell SS. Enhanced performance in elderly subjects following bright light treatment of sleep maintenance insomnia. J Sleep Res 1996; 5: $165-72$.

47 Asplund R. Sleep disorders in the elderly. Drugs Aging 1999; 14: 91-103.

48 Campbell SS, Murphy PJ, Stauble TN. Effects of a nap on night-time sleep and waking function in older subjects. J Am Geriatr Soc 2005; 53: 48-53.

49 Li F, Fisher KJ, Harmer P, Irbe D, Tearse RG, Weimer C. Tai Chi and self-rated quality of sleep and daytime sleepiness in older adults: a randomised controlled trial. J Am Geriatr Soc 2004; 52: 892-900.

50 McDowell JA, Mion LC, Lydon TJ, Inouye SK. A non-pharmacological sleep protocol for hospitalised older patients. J Am Geriatr Soc 1998; 46: 700-5.

51 Alessi CA, Schnelle JF, MacRae PG, Ouslander JG, al-Samarrai N, Simmons SF, Traub S. Does physical activity improve sleep in impaired nursing home residents? J Am Geriatr Soc 1995; 43: 1098-102.

52 Ouslander JG, Connell BR, Bliwise DL, Endeshaw Y, Griffiths P, Schnelle JF. A non-pharmacological intervention to improve sleep in nursing home patients: results of a controlled clinical trial. $\mathrm{J} \mathrm{Am}$ Geriatr Soc 2006; 54: 38-47.

53 Everitt DE, Avorn J, Baker MW. Clinical decision making in the evaluation and treatment of insomnia. Am J Med 1990; 89: 357-62.

54 Morin CM, Vallières A, Guay B, Ivers H, Savard J, Mérette C, Bastien C, Baillargeon L. Cognitive behavioural therapy, singly and combined with medication, for persistent insomnia: a randomised controlled trial. JAMA 2009; 301: 2005-15.

55 Ancoli-Israel S, Richardson GS, Mangano RM, Jenkins L, Hall P, Jones WS. Long-term use of 
sedative hypnotics in older people with insomnia. Sleep Med 2005; 6: 107-13.

56 Woodward MC. Managing insomnia in older people. J Pharm Pract Res 2007; 37: 236-41.

57 Holbrook AM, Crowther R, Lotter A, Cheng C, King D. Meta-analysis of benzodiazepine use in the treatment of insomnia. Can Med Assoc J 2000; 162: 225-33.

58 Dündar Y, Boland A, Strobl J, Dodd S, Haycox A, Bagust A, Bogg J, Dickson R, Walley T. Newer hypnotic drugs for the short-term management of insomnia: a systematic review and economic evaluation. Health Tech Assess 2004; 8: 1-125.

59 Glass J, Lanctôt KL, Herrman N, Sproule BA, Busto UE. Sedative hypnotics in older people with insomnia: meta-analysis of risks and benefits. $B M J$ 2005; 331: 1169.

60 Krystal AD, Walsh JK, Laska E, Caron J, Amato DA, Wessel TC, Roth T. Sustained efficacy of eszopiclone over 6 months of nightly treatment: results of a randomised, double blind, placebo-controlled study in adults with chronic insomnia. Sleep 2003; 26: 793-99.

61 Smith MT, Perlis ML, Park A, Smith MS, Pennington J, Giles DE, Buysse DJ. Comparative meta-analysis of pharmacotherapy and behaviour therapy for persistent insomnia. Am J Psychiatry 2002; 159: 5-11.

62 Wade AG, Ford I, Crawford G, McMahon AD, Nir T, Laudon M, Zisapel N. Efficacy of prolonged release melatonin in insomnia patients aged 55-80 years: quality of sleep and next-day alertness outcomes. Curr Med Res Opin 2007; 23: 2597-605.

63 Lemoine P, Nir T, Laudon M, Zisapel N. Prolonged release melatonin improves sleep quality and morning alertness in insomnia patients aged 55 years and older and has no withdrawal effects. J Sleep Res 2007; 66: 372-80.

64 Mini LJ, Wang-Weigand S, Zhang J. Self-reported efficacy and tolerability of ramelteon $8 \mathrm{mg}$ in older adults experiencing severe sleep-onset difficulties. Am J Geriatr Pharmacother 2007; 5: 177-84.
65 Stevinson C, Ernst E. Valerian for insomnia: a systematic review of randomised clinical trials. Sleep Med 2000; 1: 91-99.

66 Taibi DM, Vitiello MV, Barsness S, Elmer GW, Anderson GD, Landis CA. A randomised clinical trial of valerian fails to improve self-reported polysomnographic and actigraphic sleep in older women with insomnia. Sleep Med 2009; 10: 319-28.

67 Koetter U, Schrader E, Kaufeler R, Brattstrum A. A randomised, double blind, placebo-controlled, prospective clinical study to demonstrate clinical efficacy of a fixed valerian hops extract combination (Ze91019) in patients suffering from non-organic sleep disorder. Psychother Res 2007; 21: 847-51.

68 Schutte-Rodin S, Broch L, Buysse D, Dorsey C, Sateia M. Clinical guidelines for the evaluation and management of chronic insomnia in adults. J Clin Sleep Med 2008; 4: 487-504.

69 Woodward M. Deprescribing: achieving better health outcomes for older people through reducing medications. J Pharm Pract Res 2003; 33: 323-28.

70 Woodward MC. Hypnotics - options to help your patients stop. Aust Fam Physician 2000; 10: 939-44.

71 Woodward MC. Hypnosedatives in the elderly. A guideline to appropriate use. CNS Drugs 1999; 11: 263-76.

72 van Vlier P, Van der Mast RC, van den Bruek M, Westendorp RC, de Craen AJ. Use of benzodiazepines, depressive symptoms and cognitive function in old age. Int J Geriatr Psychiatry 2009; 24: 500-8.

73 Elliott RA, Woodward MC, Oborne CA. Improving benzodiazepine prescribing for elderly hospital inpatients using audit and multidisciplinary feedback. Intern Med J 2001; 31: 529-35.

74 Martin JL, Fiorentino L, Jouldjian S, Josephson $\mathrm{KR}$, Alessi CA. Sleep quality in residents of assisted living facilities, effect on quality of life, functional status and depression. J Am Geriatr Soc 2010; 58: 829-36. 